\title{
A Three Layer Model for Oil Tank Fires
}

\author{
ZHI-XIN WANG \\ Tianjin Fire Research Institute \\ PO Box 27 \\ Tianjin, PRC
}

\begin{abstract}
A three layer model for oil tank fires, which can be used to calculate heat transfer and burning rates more accurately, is studied theoretically and experimentally. It can also be used to explain the important role played by the ullage (or air space) in oil tank fires. The validity of this model has been established by burning jet fuel in an oil tank $1.6 \mathrm{~m}$ in diameter and $1.5 \mathrm{~m}$ high.
\end{abstract}

\section{KEYWORDS: FIRE MODEL, TANK FIRES, HEAT TRANSFER, RADIATION FEEDBACK, BURNING RATE}

\section{INTRODUCTION}

Oil tank and tanker fires form a large proportion of industrial fires and cause many casualties as well as economic losses. ${ }^{1,2}$ Until now, it had usually been assumed that there is only direct radiation in the heat transfer between the flame and surface of the fuel. Sometimes the geometric factor, i.e. the distance between the flame and the fuel surface, was considered. The heat transfer of tank fires in the literature is represented simply by

$\mathrm{q}=\alpha \varepsilon_{\mathrm{s}} \sigma\left(\mathrm{T}_{\mathrm{f}}^{4}-\mathrm{T}_{\mathrm{s}}^{4}\right)$

but calculations from these equations differ significantly from experimental measurements. It is therefore difficult to analyze fully tank fires and to suggest the best methods for effectively fighting such fires. In other words, the direct radiation heat transfer theory is not correct for tank fires.

Our experiments have shown that inclusion of the ullage, which lies between the bottom of the flame and the fuel surface, is very important to the treatment of oil tank combustion where fuel vapor, air, soot and combustion products affect radiative transfer to the fuel surface. Until now, most papers on liquid fuel burning analyzed the heat transfer by a flame-fuel two layer model. According to this model, however, the calculated results, even for pool fires, differ from the test results.

Our tests have shown that the ullage contains not only a large quantity of fuel vapor but also air, smoke and combustion products. In fact, the ullage has an obvious thermal shielding effect on the fuel surface. If this effect is neglected, a serious error will result. To overcome this shortcoming, a flame-ullage-fuel surface three layer model is presented here. 


\section{THREE LAYER MODEL}

\section{Basic Assumptions}

The following basic assumptions are made:

1. The bottom of the flame is a grey plane with a constant emissivity which is parallel to the fuel surface.

2. Radiation is the dominant mechanism for heating the fuel surface. Heat transfer from conduction and convection are taken to be negligible.

3. The ullage is a grey gas layer and has a uniform "grey scale" through this layer.

4. The fuel surface is a grey plane with a constant emissivity. analysis.

Obviously these assumptions are simplifications, but they are necessary for easy

\section{Radiation to the Fuel Surface}

For simplicity, we first analyze the case of a tank with an infinite diameter. This corresponds to a situation where the radiation between two parallel plates is separated by a grey gas layer in a one dimension field. If this system is in equilibrium without an internal source, the total radiation between the parallel infinite planes separated by a grey gas layer is equal to the sum of radiation between the grey gas and the fuel surface and the direct radiation between the flame and the fuel surface.

Direct radiation. Let $\mathrm{dA}_{1}$ be representative of the fuel surface $S$ and $\mathrm{dA}_{2}$ of a circular annulus generated about the $X$ axis, as shown in Fig. 1. The emission in direction $\theta$ per unit solid angle is $E_{s} d A_{1} \operatorname{Cos} \theta / \pi$ and the solid angle subtended by $d_{2}$ at $d A_{1}$ is $\mathrm{dA}_{2} \cos \theta / \mathrm{r}^{2}$. The fraction transmitted is $\exp (-\mathrm{Kr})$ and the direct exchange between the flame and the fuel surface is:

$$
Q_{\mathrm{f} ; \mathrm{s}}=\left(\mathrm{E}_{\mathrm{f}}-\mathrm{E}_{\mathrm{s}}\right) \int_{\mathrm{S}} \int_{\mathrm{F}} \mathrm{dA_{1 }} \cos \theta \mathrm{dA} \mathrm{A}_{2} \cos \theta \mathrm{e}^{-\mathrm{Kr}} / \pi \mathrm{r}^{2}
$$

$r=\mathrm{L} / \operatorname{Cos} \theta, d A_{2}=2 \pi r^{2} \operatorname{tg} \theta d \theta$

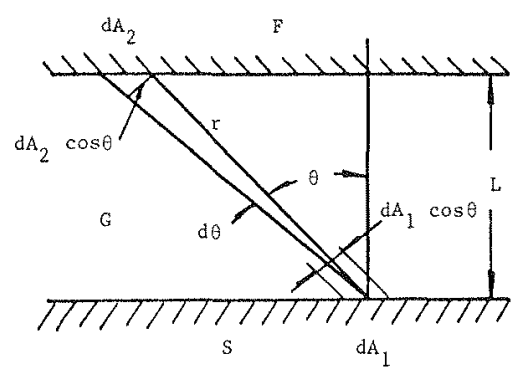

Figure 1. Direct radiation between the flame and the oil surface 
and the radiation per unit area is:

$\mathrm{q}_{\mathrm{f}=\mathrm{s}}=\mathrm{Q}_{\mathrm{f}=\mathrm{s}} / \int \mathrm{dA}_{1}$

$\mathrm{q}_{\mathrm{f}} /\left(\mathrm{E}_{\mathrm{f}}-\mathrm{E}_{\mathrm{s}}\right)=\int_{0}^{\pi / 2} 2 \operatorname{Sin} \theta \operatorname{Cos} \theta \mathrm{e}^{-\mathrm{KL} / \cos \theta} \mathrm{d} \theta$

\section{Let $t \rightarrow 1 / \operatorname{Cos} \theta$}

then

$\mathrm{q}_{\mathrm{f} \div \mathrm{s}} /\left(\mathrm{E}_{\mathrm{f}}-\mathrm{E}_{\mathrm{s}}\right)=2 \int_{1}^{\infty} \mathrm{e}^{-\mathrm{KLt}} \mathrm{dt} / \mathrm{t}^{3}=2 \varepsilon_{3}(\mathrm{KL})=2 \varepsilon_{3}(\tau)$

where $\varepsilon_{3}(\tau)=\varepsilon_{3}(\mathrm{KL})$ is a third exponential integral. Thus the direct radiation flux density between the flame and fuel surface is:

$\mathrm{q}_{\mathrm{f} \rightarrow \mathrm{s}}=2 \varepsilon_{3}(\tau)\left(\mathrm{E}_{\mathrm{f}}-\mathrm{E}_{\mathrm{s}}\right)$

The relationship between $q_{f \ni s}$ and $\tau$ is shown in Fig. 2 where it can be seen that when $\tau>3$, the direct exchange between the flame and the fuel surface nearly disappears, i.e., the fuel surface will be fully masked by the ullage. The fuel only receives radiation from the gas layer (ullage) and the gas layer only receives radiation from the flame.

$\tau<0.1$. This corresponds to the early stage of tank fires. Since this stage is very short, we do not discuss it in detail.

$\tau \geq 0.1$. This is the usual case for the combustion of tank fires, and it represents a much more complex situation. To obtain results, both the diffusion characteristics of radiation and the boundary conditions need to be considered. Select a coordinate system

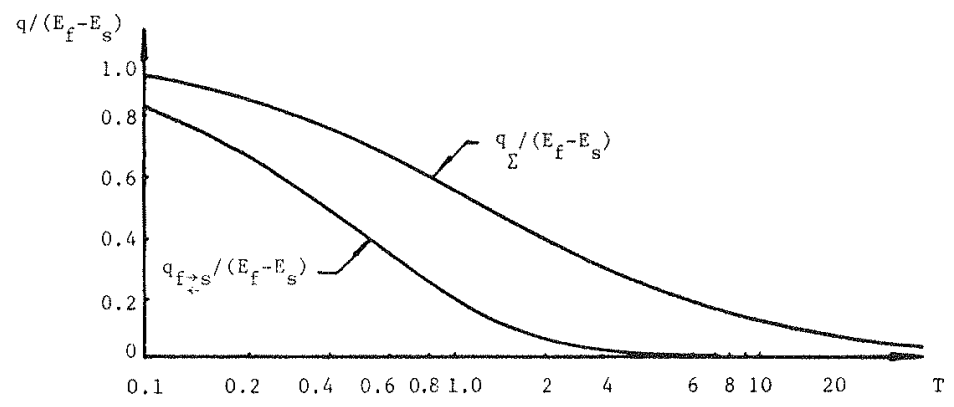

Figure 2 The relationship between the general radiation flux density $\left(\mathrm{q}_{\Sigma}\right)$, the heat radiation received by oil surface $\left(\mathrm{q}_{f \vec{z} \mathrm{~s}}\right)$ and the optical thickness of the middle layer $(\tau)$ 
(see Fig. 3) so that the plane of interest in the grey gas is parallel to the $\mathrm{YZ}$ axes at $\mathrm{X}=0$, and also denotes the one-way flux densities in the direction of increasing $X$ by $q_{+}$, as well as decreasing $X$ by $q$. The flux density leaving the grey gas layer is composed of emitted and scattered contributions ${ }^{3}$. The radiation emitted by a volume element, $\mathrm{dV}$, is $4 \mathrm{KdVW}_{\mathrm{g}}(\mathrm{X})$ and

$W_{g}(X)=(1-\omega) E_{g}(X)+\omega H$

where the albedo for scatter of grey gas is:

$\omega=\mathrm{K}_{\mathrm{s}} / \mathrm{K}=\mathrm{K}_{\mathrm{s}} /\left(\mathrm{K}_{\mathrm{s}}+\mathrm{K}_{\mathrm{a}}\right)$

A fraction dACos $\theta / 4 \pi r^{2}$ is directed towards the surface $\mathrm{dA}$ and from this $\exp (-\mathrm{Kr})$ is transmitted. The flux density at $\mathrm{dA}$ due to radiation emitted at $\mathrm{dV}$ is:

$4 \mathrm{KdVW}_{\mathrm{g}}(\mathrm{X}) \operatorname{Cos} \theta \mathrm{e}^{-\mathrm{Kr}} / 4 \pi \mathrm{r}^{2}$

Integrate Eq. 5 over $\mathrm{x}$ from 0 to $\infty, \theta$ from 0 to $\pi / 2$ and let $t=1 / \operatorname{Cos} \theta$ which gives

$\mathrm{q}_{+}=2 \int_{0}^{\infty} \mathrm{KW}(\mathrm{x}) \varepsilon_{2}(\mathrm{KL}) \mathrm{dx}$

where $\varepsilon_{2}(\mathrm{Kx})$ is the second exponential integral. If $\mathrm{W}_{\mathrm{g}}(\mathrm{x})$ is represented by a Taylor series, then the integration of each term by parts is:

$\mathrm{q}_{+}=\mathrm{W}_{\mathrm{g}}(0)-\frac{2}{3 \mathrm{~K}} \mathrm{~W}_{\mathrm{g}}^{\prime}(0)+\frac{1}{2 \mathrm{~K}^{2}} \mathrm{~W}_{\mathrm{g}}^{\prime \prime}(0)-\frac{2}{5 \mathrm{~K}^{3}} \mathrm{~W}_{\mathrm{g}}^{\prime \prime \prime}(0)+\cdots \cdots$

Integrate Eq. 5 over $x$ from 0 to $-\infty$, and $\theta$ from 0 to $\pi / 2$ to give

$q_{-}=W_{g}(0)+\frac{2}{3 K} w_{g}^{\prime}(0)+\frac{1}{2 K^{2}} W_{g}^{\prime \prime}(0)+\frac{2}{5 K^{3}} w_{g}^{\prime \prime}(0)+\cdots \cdots$

The net flux across the plane $S$ then is:

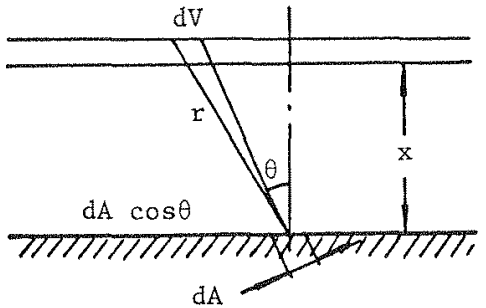

Figure 3 Radiation between gas and oil surface 
$q=q_{+}-q_{-}=-4 \sum_{m=1}^{\infty} \frac{d^{(2 m-1)} W_{g}(0)}{(2 m+1) K^{(2 m-1)} d x^{(2 m-1)}}$

If the variation in the flux density over one mean free path is small enough, then only the first term in Eq. 9 needs to be retained.

$q=-4 d W_{g}(0) / 3 K d x$

If the boundary is specific with regards to the bulk materials with a refractive index near 1 , i.e., only gases where $\mathrm{W}_{\mathrm{g}}$ is distributed linearly in the gas, then

$\mathrm{dW}_{\mathrm{g}}(0) / \mathrm{dx}=\mathrm{dW}_{\mathrm{g}}(\mathrm{x}) / \mathrm{dx}=\mathrm{dW}_{\mathrm{g}} / \mathrm{dx}$

and the radiation between the plane and the grey gas is, then

$\mathrm{q}_{\mathrm{g} \Rightarrow \mathrm{s}}=-4 \mathrm{dW} / \mathrm{g} \mathrm{Kdx}$

If the plane $S$ (fuel surface) is a grey body, its emissive power is $E_{s}$, and its emissivity is $\varepsilon_{\mathrm{s}}$ then

$-q_{g \neq s}=\varepsilon_{s}\left(q_{-}-E_{s}\right)$

Combining Eqs. 8, 9, and 13 gives

$W_{g}(0)-E_{s}=-q_{g} \frac{1}{s}\left(1 / \varepsilon_{s}-1 / 2\right)$

Integrating Eq. 12 from $\mathrm{x}=0$ to $\mathrm{L}$, combine with Eq. 14 to give

$q_{g} \frac{s s}{z}=-\left(W_{g}-E_{s}\right) /\left(3 \tau / 4+1 / \varepsilon_{s}-1 / 2\right)$

If there is no scatter in the grey gas, from Eq. 4 with $\omega=0, \mathrm{~W}_{\mathrm{g}}=\mathrm{E}_{\mathrm{g}}$; and $\mathrm{K}=\mathrm{K}_{\mathrm{a}}$;

$\tau=\mathrm{K}_{\mathrm{a}} \mathrm{L} ; \mathrm{K}_{\mathrm{s}}=0$ so that

$\mathrm{q}_{\mathrm{g}>\mathrm{s}}=-\left(\mathrm{E}_{\mathrm{g}}-\mathrm{E}_{\mathrm{s}}\right) /\left(3 \tau / 4+1 / \varepsilon_{\mathrm{s}}-1 / 2\right)$

Total radiation between the flame and fuel surface. The heat transfer between the flame (F) and ullage $(G)$, as well as between the ullage $(G)$ and fuel surface $(S)$ can be written from Eq. 14 as

$W_{g}(0)-E_{s}=-\left(1 / \varepsilon_{s}-1 / 2\right) \cdot 2 / 3 K \cdot\left(d W_{g} / d x\right)_{x=L}$

$E_{f}-W_{g}(0)=-\left(1 / \varepsilon_{f}-1 / 2\right) \cdot 2 / 3 K \cdot\left(d W_{g} / d x\right)_{x=0}$

When $x=0 ; W_{g}-E_{s}=0 ; x=L ; W_{g}-E_{s}=-3 q_{E} \tau / 4$

then $W_{g}(0)-E_{s}=-q_{\Sigma}\left(3 \tau / 4+\left(1 / \varepsilon_{s}-1 / 2\right)\right)$

$E_{f}-W_{g}(0)=-q_{\Sigma}\left(1 / \varepsilon_{f}-1 / 2\right)$ 
Combining Eq. 19 with Eq. 20 gives the general radiation between the flame (through the ullage) and the fuel surface:

$\mathrm{q}_{\Sigma}=\frac{E_{\mathrm{f}}-\mathrm{E}_{\mathrm{s}}}{3 \tau / 4+1 / \varepsilon_{\mathrm{f}}+1 / \varepsilon_{\mathrm{s}}-1}$

Boundary changes in the integration. A real tank reacts to boundary changes in the integration. For simplicity, the results obtained above can be corrected by a coefficient ${ }^{1}$, which is derived from the radiation between two parallel grey discs with common centers normal to their plane and separated by a distance $\mathrm{L}$.

$Q_{p}=\varepsilon\left(E_{1}-E_{2}\right) S_{12}$

$S_{12}=\frac{\pi}{4}\left\{\sqrt{\left(\left(D_{1}+D_{2}\right) / 2\right)^{2}+L^{2}}-\sqrt{\left(\left(D_{1}-D_{2}\right) / 2\right)^{2}-L^{2}}\right\}^{2}$

The stoichiometric flux density $q_{p}=Q_{p} / S_{12}$, when $L=0$ is

$\mathrm{q}_{\mathrm{p}}=\mathrm{Q}_{\mathrm{p}} /\left\{\pi\left(\left(\mathrm{D}_{1}+\mathrm{D}_{2}\right) / 2\right)^{2} / 2\right\}$

Let $\alpha=\mathrm{q}_{\mathrm{p}} / \mathrm{q}_{\mathrm{p} 0}$ and $\mathrm{D}_{1}=\mathrm{D}_{2}$ then

$\alpha=\left(\left(\sqrt{D^{2}+L^{2}-L}\right) / D\right)^{2}$

Obviously, $0<\alpha<1$, and then the total radiation flux density is

$\mathrm{q}_{\Sigma}=\sigma\left(\mathrm{E}_{\mathrm{f}}-\mathrm{E}_{\mathrm{s}}\right) /\left(3 \tau / 4+1 / \varepsilon_{\mathrm{f}}+1 / \varepsilon_{\mathrm{s}}-1\right)$

or

$\mathrm{q}_{\Sigma}=\alpha \sigma\left(\mathrm{T}_{\mathrm{f}}^{4}-\mathrm{T}_{\mathrm{s}}^{4}\right) /\left(3 \tau / 4+1 / \varepsilon_{\mathrm{f}}+1 / \varepsilon_{\mathrm{s}}-1\right)$

\section{Oil Energy Balance}

As can be seen from Fig. 4, the total flux density at the fuel surface is q, the burning rate of the fuel is $V_{a}$, the heated layer downward expanding speed is $V_{b}$, then

$\mathrm{q}_{\Sigma}=\rho h \mathrm{~V}_{\mathrm{a}}+\mathrm{c} \rho \mathrm{V}_{\mathrm{b}}\left(\mathrm{T}_{\mathrm{s}}-\mathrm{T}_{0}\right)$

From Eq. 23

$\rho h V_{a}+c \rho V_{b}\left(T_{s}-T_{0}\right)=\frac{\alpha \sigma\left(T_{f}^{4}-T_{s}^{4}\right)}{0.75 \tau+\varepsilon_{f}^{-1}+\varepsilon_{s}^{-1}-1}$

When $V_{b}=V_{a}$, the burning rate of a tank fire in a steady state is: 


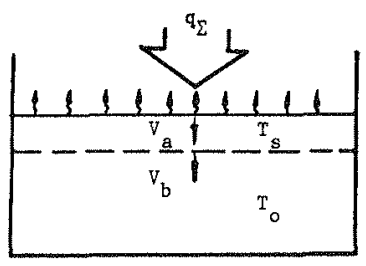

Figure 4 Oil Energy Balance

$$
\mathrm{V}=\frac{\alpha \sigma\left(\mathrm{T}_{\mathrm{f}}^{4}-\mathrm{T}_{\mathrm{s}}^{4}\right)}{\rho\left(0.75+\varepsilon_{\mathrm{f}}^{-1}+\varepsilon_{\mathrm{s}}^{-1}-1\right) \cdot\left(\mathrm{h}+\mathrm{c}\left(\mathrm{T}_{\mathrm{s}}-\mathrm{T}_{0}\right)\right)}
$$

\section{EXPERIMENTS}

To test the three layer model, four fire tests on a water cooled tank $1.6 \mathrm{~m}$ in diameter and $1.5 \mathrm{~m}$ high have been performed in a very large building, $247 \mathrm{~m}$ long $\times 82.4 \mathrm{~m}$ wide $\mathrm{x}$ $53.2 \mathrm{~m}$ high. By probing the ullage, measurements of the temperature, gas concentrations and smoke concentrations were taken during the fire tests employing Jet A1, a British aviation kerosene. Measurements of total heat transfer to a Gardon type heat flux meter floated on the surface of the fuel, together with thermocouple temperatures immersed in the fuel allow an estimate of the effects of blocking radioactive feedback to the fuel by combustion products entrained into the ullage. The measurement range of the flux meter is 0.1 to $8 \mathrm{~W} / \mathrm{cm}^{2}$, with a sensitivity of not less than $0.1 \mathrm{~W} / \mathrm{cm}^{2}$, and a response time of less than 10 seconds. A diagram of the experimental sampling system is shown in Fig. 5. In addition to the above measurements, photographic records of the flame were obtained by high speed cinematography. The flame length was recorded by long-time exposure photography, as well as by conventional video and short-time exposure photography.

\section{Visual Observations}

Two clear and distinct observations give useful insight into tank fire combustion. The first, which could only be observed in the cinematography, falling on cold entrained air "through" the flame envelope near the top of the tank at discrete times within the flame pulsation $(0.5-1 \mathrm{~Hz})$. This is presumably the mechanism for drawing combustion products into the ullage. The second, flame lift off occurs locally at several locations around the perimeter of the tank. Here the local velocities must exceed those of the burning velocity. This effect becomes more pronounced with increased ullage. Through the gaps in the flame, it is possible to discern fuel rich combustion inside the main envelope, close to the fuel surface, giving a dark red and smoky appearance through the "window" in the flame.

\section{Flame Characteristics}

A high level (the distance between the fuel surface and the tank top is D/10 to D/5) tank fire is very similar to a pool fire. Its flame is usually a turbulent buoyant diffusion flame. The base of the flame is like a cone. There is negative pressure, about $0.5 \mathrm{bar}$, at the tank center near the fuel surface. The negative pressure sucks the surrounding air towards the axis of the tank, but as the fuel level is high, air cannot be sucked into the tank, 


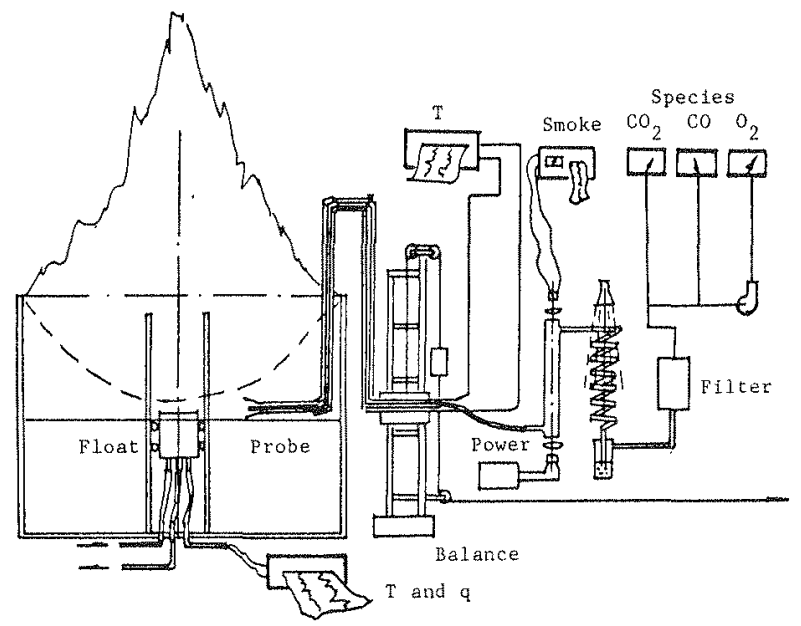

Figure 5 Experimental sampling system

and only an inverted circular valley is formed by the air, as shown in Figs. 6a and $6 \mathrm{~b}$.

When the fuel level was decreased to the range $\mathrm{D} / 5$ to $\mathrm{D} / 3$ (middle level tank fires), air is sucked into the tank and ullage is being formed, but at the same time the burning gas rises and the cold air and hot gases form a jagged interlocking pattern. There are many "fire balls" on the top of the tank. The flame has a neck and also has obvious pulsation with mushroom clouds, as shown in Fig. 6c.

When the fuel level is lower than $\mathrm{D} / 2$, cold air gets into the tank, but has difficulty penetrating into the flame. As the concentration of $\mathrm{O}_{2}$ decreases in the ullage, combustion as well as the negative pressure inside the tank become increasingly weak. A large quantity of the fuel rich combustion products and smoke escape from the tank along the wall. The flame is shorter and the neck disappears. There are some non-burning fuel rich "black holes" near the perimeter of the tank, as shown in Fig. 6d.

The measurements of temperatures, concentrations of $\mathrm{O}_{2}, \mathrm{CO}, \mathrm{CO}_{2}$ and smoke obscuration (for low level fire tests) are shown in Fig. 7. These measurements give clear evidence that combustion products, smoke and air are present between the fuel surface and the top of the tank. The photographic records also support this view. From Fig. 6 it can be seen that the ullage thickness increases with a decrease of the fuel level. If the value is large enough, it should not be neglected for tank fires.

The flux density measured by the Gardon total heat flux meter and the measurements of irradiance from the base of the fire, as measured by the total radiation pyrometer ${ }^{4}$, are given in Fig. 8. Both the flux density and the flame irradiance decrease with a lowering of the fuel level. This means that the ullage thickness depends on the burning period and the drop in fuel. The longer the burning period, the larger is the effect of radiation absorption by the ullage.

\section{Comparisons}

Since most oil tank fires occur with a substantial ullage, "low level" test data are used here to test the model. These test data are as follows: fuel level $73.4 \mathrm{~cm}$, burning 


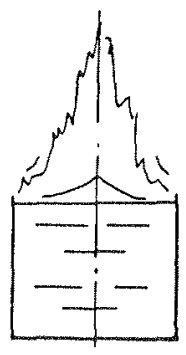

a

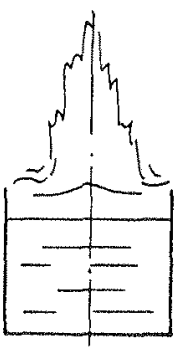

b

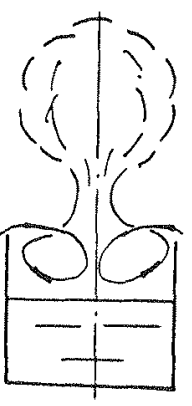

c

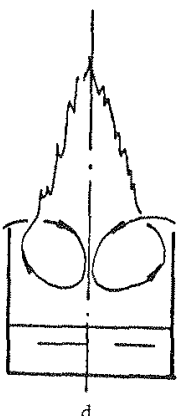

Figure 6 Typical tank fire flames; a. high level, b. some fuel burn out, c. middle level, d. low level.

time 40 minutes, mean burning time $1.6 \mathrm{~mm} / \mathrm{min}$, thickness of the ullage $\mathrm{L}=0.25 \mathrm{~m}$, mean extinction coefficient $K=10 \mathrm{~m}^{-1}$, emissivity of the kerosene flame ${ }^{5} \varepsilon_{\mathrm{f}}=0.92$, density of the JET A1 (at $100^{\circ} \mathrm{C}$ ) 0.766 , specific heat $\mathrm{c}=2.38 \mathrm{~J} / \mathrm{gK}$, latent heat $\mathrm{h}=317.15 \mathrm{~J} / \mathrm{g}$, $\mathrm{T}_{\mathrm{f}}=1123 \mathrm{~K}, \mathrm{~T}_{\mathrm{s}}=463 \mathrm{~K}, \mathrm{~T}_{\mathrm{o}}=280 \mathrm{~K}$, emissivity of the fuel surface $\varepsilon_{\mathrm{s}}=0.96$.

The burning rate based on the test is $1.6 \mathrm{~mm} / \mathrm{min}$, thus the total heat required to rise one square centimeter of fuel surface to vaporize it and the heating of the fuel beneath the surface should be

$\dot{q}=\rho\left(h+c\left(T_{s}-T_{0}\right)\right) V=1.54 W / c^{2}$

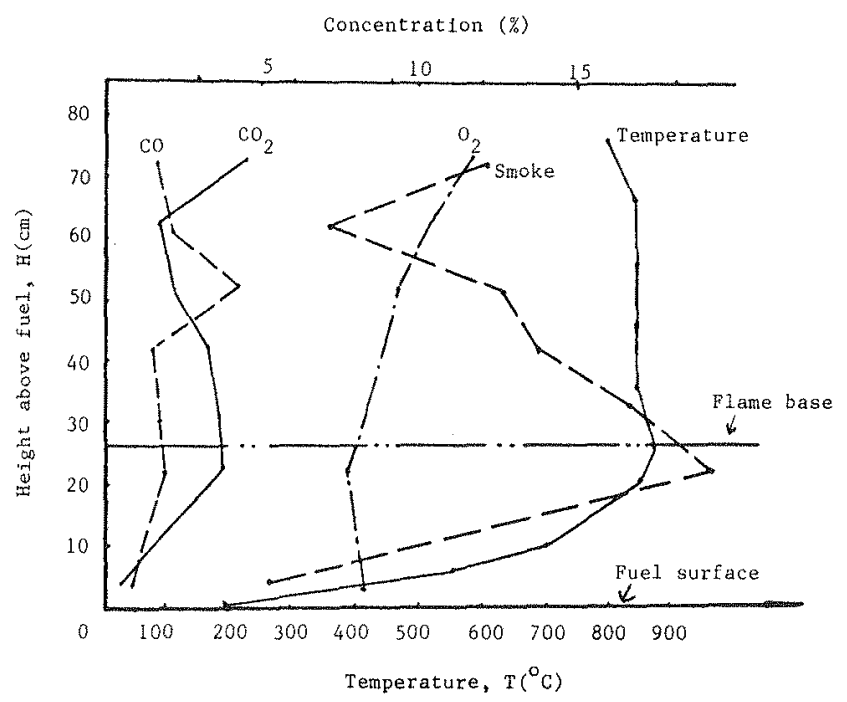

Figure 7 Combustion products, $\mathrm{O}_{2}$ and $\mathrm{T}$ profiles inside the tank 


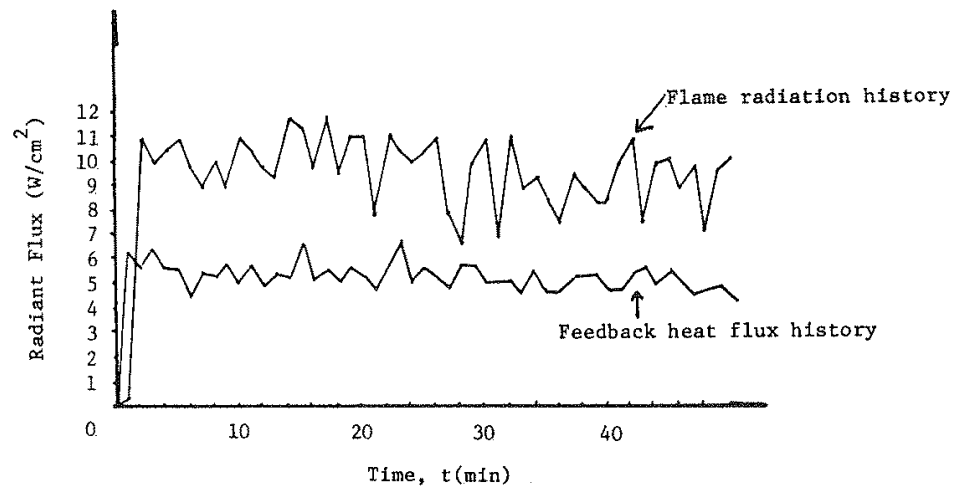

Figure 8 Flame radiation and feedback heat flux histories on the fuel surface.

but the heat flux recorded by the heat flux meter is around 4 to $5.5 \mathrm{~W} / \mathrm{cm}^{2}$. Obviously, a large discrepancy exists. The explanation must be that (except for the maximum convective heat transfer at the tank center) the difference in temperature of the receiving surfaces, namely the fuel surface (about $200^{\circ} \mathrm{C}$ ) and the water-cooled flux meter $\left(8^{\circ} \mathrm{C}\right.$ ), give rise to a substantially larger convective heat transfer from the boiling fuel to the cold sensor or it may cause condensation of fuel vapors on the flux meter.

According to the three layer model, the general radiation flux density received by the fuel surface is:

$\alpha=\left(\sqrt{D^{2}+L^{2}-L}\right) / D=0.856$

$\tau=\mathrm{KL}=2.5$

$\mathrm{q}=2.5 \mathrm{~W} / \mathrm{cm}^{2}$

The calculated steady burning rate according to $\mathrm{Eq} .25$ is:

$\mathrm{V}=2.6 \mathrm{~mm} / \mathrm{min}$

We can see from the above that the calculated results are close to the test results. The reason for the difference must be attributed to the imprecision of the measurements of $\mathrm{K}$ and $\mathrm{L}$. If we had used Eq. 1, then

$\mathrm{q}_{\Sigma}=\alpha \varepsilon_{\mathrm{S}} \sigma\left(\mathrm{T}_{\mathrm{f}}^{4}-\mathrm{T}_{\mathrm{s}}^{4}\right)=7.2 \mathrm{~W} / \mathrm{cm}^{2}$

$\mathrm{V}=\mathrm{q}_{\Sigma} / \rho\left(\mathrm{h}+\mathrm{c}\left(\mathrm{T}_{\mathrm{s}}-\mathrm{T}_{\mathrm{C}}\right)\right)=7.5 \mathrm{~mm} / \mathrm{min}$

which differ considerably from the test results.

\section{CONCLUSIONS}

Our conclusions have illustrated that there is a non-combustion layer, the ullage between the fuel surface and the flame. The thickness of the ullage depends on the fuel, the tank diameter, and the fuel level. The negative pressure inside the tank sucks the surrounding air, penetrates the flame envelope and reaches into the ullage. Accompanying 
the entrained air, some smoke and combustion products reach to the ullage, causing the ullage to become a grey layer. Air, smoke and combustion products entrained into the ullage come mainly from the axis of the tank. This behavior of tank fires is clear support for the validity of the three layer model.

The calculation results of tank fires using the three layer model are much better than those of other models. In fact, Eq. 1 represents a special occurrence of Eq. 23, i.e. the case of pool fires which have no ullage, or only a very thin one.

The three layer model provides a theoretical basis for developing new fire fighting methods. From Eq. 23

$$
\mathrm{q}_{\varepsilon}=\frac{\alpha \sigma\left(\mathrm{T}_{\mathrm{f}}^{4}-\mathrm{T}_{\mathrm{s}}^{4}\right)}{0.75+\varepsilon_{\mathrm{f}}^{-1}+\varepsilon_{\mathrm{s}}^{-1}-1}
$$

we can see that there are three many ways to extinguish a tank fire. One is to decrease the temperature and emissivity of the flame, which is the most effective method for putting out a tank fire. The second method is to decrease the emissivity of the fuel surface $\varepsilon_{\mathrm{s}}$. Until now, most research on fighting tank fires have focused on this area, and some fire fighting foams have been developed for this purpose. No attention has been paid, until now, to improving the emissivity and thermal shielding effect of the foams. The third method is to increase the thickness and extinction coefficient, i.e., increase the optical thickness of the ullage. Following this theory, Chinese engineers have invented a new fire extinguishing system, a smoke system, and we believe other new techniques will soon be developed.

\section{NOMENCLATURE}

$$
\begin{array}{ll}
c & \text { Specific heat } \\
D & \text { diameter of tank } \\
\mathrm{E}_{1}, \mathrm{E}_{2} & \text { diameter of discs } \\
\mathrm{E}_{\mathrm{f}} & \text { black body flux density of flame } \\
\mathrm{E}_{\mathrm{g}} & \text { black body emissive power of grey gas } \\
\mathrm{E}_{\mathrm{s}} & \text { black body flux density of fuel surface } \\
\mathrm{F} & \text { bottom of flame } \\
\mathrm{h} & \text { latent heat } \\
\mathrm{H} & \text { incident radiant flux density } \\
\mathrm{K} & \text { extinction coefficient } \\
\mathrm{K}_{\mathrm{a}} & \text { absorption coefficient } \\
\mathrm{K}_{\mathrm{s}} & \text { scatter coefficient } \\
\mathrm{L} & \text { thickness of ullage } \\
\mathrm{q} & \text { radiation received by fuel surface }
\end{array}
$$


$\mathrm{Q}_{\mathrm{p}} \quad$ energy received by a body during radiative heat exchange between two grey bodies located arbitrarily in space

$S$ fuel surface

$\mathrm{S}_{12} \quad$ mutual radiation surface for two parallel disks with centers on the common normal to their plane

$\mathrm{T}_{0} \quad$ temperature of fuel (bottom layer)

$\mathrm{T}_{\mathrm{f}} \quad$ temperature of flame

$\mathrm{T}_{\mathrm{s}} \quad$ temperature of fuel surface

$\mathrm{V}_{\mathrm{a}} \quad$ heated layer downward expending speed

$\mathrm{W}_{\mathrm{g}} \quad$ leaving-flux density (radiosity) of grey gas

$\alpha \quad$ geometry coefficient

$\varepsilon_{\mathrm{f}} \quad$ emissivity of flame

$\varepsilon_{\mathrm{s}} \quad$ emissivity of fuel surface

$\rho \quad$ density

$\tau \quad$ optical thickness of ullage

$\omega \quad$ albedo for scatter of grey gas.

\section{ACKNOWLEDGMENTS}

The author wishes to thank Dr. P. H. Thomas, Mr. G. Cox, Mr. P. Fardell, Mr. H. Wraight, Mrs. S. Rogers and many other staff of the Fire Research Station, Borehamwood, UK for discussions and help with this work.

\section{REFERENCES}

1. Blinov, V. I., and Ardmeniko, I. S., "Combustion of Liquids in Tanks With Reducing the Fuel Level," Pozharnaya Profilaktika i Tushenie Pozharov-Informatsonnii, Sbornik 4 Izdatelstvo Literaturi po Stroitelstvy, Moskva, 1968.

2. Diederichsen, J., Hall, A. R., and Jeef, A. T., "The Burning of an Oil Wrecked Tanker," British Rocket Propulsion Establishment, Technical Report No. 72/9.

3. Hottel, H., Sarofim, A. F., Radiation Transfer, McGraw-Hill Book Co., New York, 1967.

4. Alger, R. S., Corlett, R. C., Gordon, A. S., and Williams, F. A., Fire Technology, $15,142,1979$.

5. Rasbash, D. J., Rogowski, Z. W., and Stark, G. W. V., Fuel, 35, 94, 1956. 